\title{
Interactive Map of Natural Reserves in Egypt Using Open-Source Web GIS Tools
}

\author{
By \\ Ahmed Mahmoud Abdelwahed
}

Assistant lecturer, specialization: production of maps and atlases and Geographic Information Systems

Prof. Ismaiel Youssff Ismaiel

Professor of Urban Geography and

Geographic Information Systems

Prof. Adel Mohamed Shawesh

Professor of Transport Geography

Dr. Mahmoud Fawzy Fara

Lecturer in Cartography and

Geographic Information Systems

Faculty of Arts, Geography Department,

Menoufia University 
INTERACTIVE MAP OF NATURAL RESERVES IN EGYPT USING OPEN-SOURGE WEB GIS TOOLS

\section{By \\ Ahmed Mahmoud Abdelwahed 1 \\ Prof. Ismaiel Youssff Ismaiel 2 \\ Prof. Adel Mohamed Shawesh 3 \\ Dr. Mahmoud Fawzy Farag 4 \\ Faculty of Arts, Geography Department, Menoufia University}

\section{Abstract \\ Natural reserves are major economic components of countries, due to their natural, human, environmental and tourism importance. Therefore, this study aims to create an interactive map of natural reserves in Egypt, which have 30 existing natural reserves, and 14 suggested natural reserves, On the other hand, today's world is moving to use technology in all directions, including maps. So, this study depends on using Open-Source Web GIS Tools in creating the interactive map, instead of traditional paper maps. Web GIS is the result of merging the advantages of geographic information systems and the possibility of the Internet. This creates maps of easy access and manipulation. Open-Source tools are free to use tools for users to develop on. This study relies on Web design programming languages (HTML - CSS - Java Script) for map creating using the Leaflet.js mapping library, and type of data Geojson, and software that uses QGIS for mapping work, and Brackets for coding.}

Key Words: Interactive Map, Web GIS, Open-Source, Nature Reserves

\section{Introduction}

Biodiversity loss due to human activities has become a major environmental problem worldwide, so establishing nature reserves to protect species and their habitats has historically been the cornerstone of biodiversity conservation (Yu, B, et al, 2016). In the management of Nature reserve IUCN has built a map database of all protected areas in the world and WEBGIS technology is sharing that map information. At the website (https://www. protectedplanet.net/en) the map information of global protected areas in the world is shown including boundaries, name, type, countries area, analysis tools (Quynh, H, et al, 2016). For decades, the main access to geographic information has been pursued only through desktop-based personal computers. During this period, it has not been possible to share information easily and efficiently with other people and organizations (Sandinska, Y, 2016). Google Maps and Google Earth, developed by Keyhole and released in 2005, have played a defining role in increasing public awareness of geospatial data, allowing users to browse geospatial data through web mapping without installing conventional GIS software (Kawasaki, A, et al, 2012).

Web GIS is a GIS applicati

on made available through a common web browser. Together with the use of the World Wide Web (Zerihun, M, 2017), it is an application that can be accessed via the Internet to manipulate, analyze, store, and use GIS features without having to use GIS software (Nizamuddin, 2017). Web GIS technology is focuses on designing and mapping for a specific

\footnotetext{
${ }^{1}$ Assistant lecturer, specialization: production of maps and atlases and Geographic Information Systems

2 Professor of Urban Geography and Geographic Information Systems

3 Professor of Transport Geography

${ }^{4}$ Lecturer in Cartography and Geographic Information Systems
} 
application or project in the GIS environment, then publishes the maps on the Internet so that an unlimited number of users can benefit from them and obtain the spatial data they need. This technology is used around the world in many applications such as weather maps, traffic maps, electronic city maps, tourist maps, and other applications (Azaz, L, 2019). Interactive map with its external database linking provides an effective way to visualize spatial data
(Wang, K, et al, 2008). For the purposes of the present work, the conception of an interactive map has seemed the proper solution in the perspective of producing a feasible operative tool (Marconcini, S, 2018). With the Web, interactive maps have become available for the average consumer. With wireless and mobile technologies, interactive maps have become ubiquitous and, in some domains of life, a part of everyday life (Sarjakoski, L, et al, 2009).

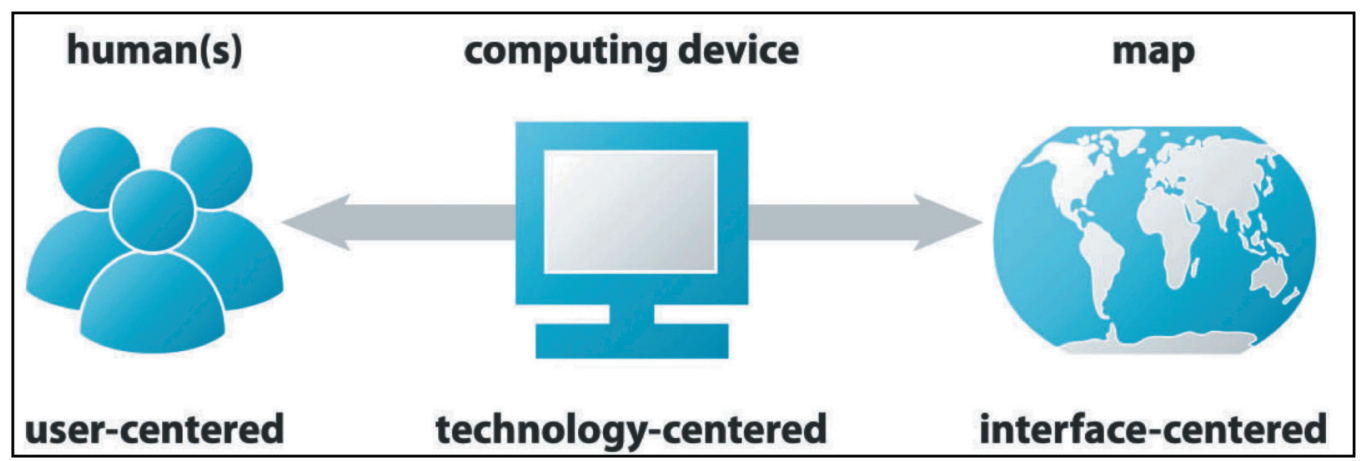

Fig. 1. Components of Cartographic Interaction: Cartographic interaction is defined as the dialogue between a human (left) and a map (right) mediated through a computing device (middle), From (Roth, $R$, 2012)

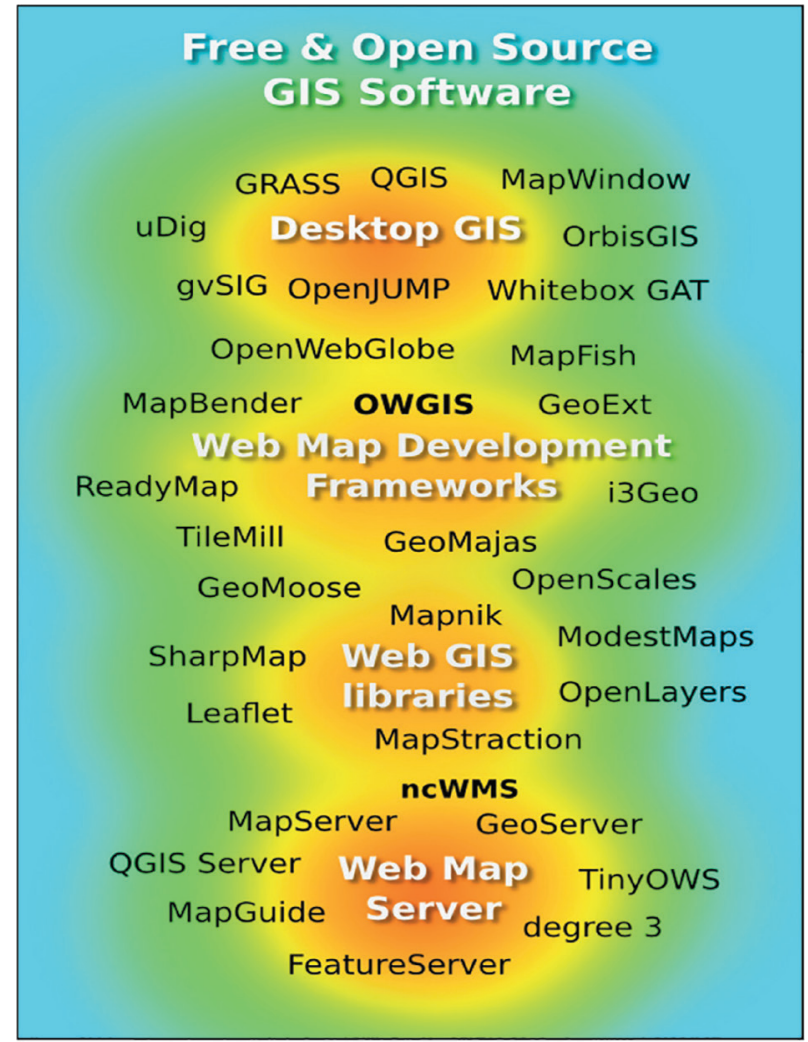

Fig. 2. Simplified schme of the free and opensource geographic information software for the web: ( Romero, $O$, et al, 2014)
Open-source software is technically defined as software in which the source code is available for modification and redistribution by the public. There are a myriad of different open-source software licenses, and the "OpenSource Initiative" (https://opensource.org/) has taken on the role of general arbiter of license correctness (Ramsey, P, 2007). Open-Source Web GIS software systems have matured over time and provided the functionality, elegance, strength, and user friendliness equivalent to that of proprietary Web GIS products (Singh, H, et al, 2014).

In this study, we will use one of the most famous libraries; leaflet Js, an open-source JavaScript library for web and mobile-friendly interactive maps (https://leafletjs.com/).

Leaflet It is one of the most popular opensource JavaScript libraries used in (Edler, D: 
2019, Singh, H: 2018, Brambilla, G: 2017, Farkas, G: 2017a, Peterson, G: 2014, Donohue, R: 2014, Muehlenhaus, I: 2014 and others). It helps create web and mobile interactive maps. It is simple, easy to use, light in weight and provides enhanced performance. It works efficiently across all major desktop and mobile platforms. As it is open-source, the developer community has contributed to create a lot of free plugins (Singh, H, et al, 2018). Of the 24 opensource libraries for creating GIS applications for the web, only five were selected which are the most effective, among them was the leaflet Library. They are considered the best solution for creating web map applications (Farkas, G, 2017b). They are lightweight that provides better performance and have been used all over the world for making web map applications (Teslya, N, 2014).

\begin{abstract}
Study Area
A web Gis application is created for the Arab Republic of Egypt where there are 30 natural reserves. Ras Muhammad is the oldest nature reserve that was declared in 1983, while the Nayazik Jabal Kamil natural reserve is the most recent; declared in 2012. It also varies according to area. El-Gelf El-Keber nature reserve is the largest with an area of $48523 \mathrm{~km} 2$. On the other hand, Salouga and Ghazal is the smallest; less than $1 \mathrm{~km} 2$. Natural reserves vary according to type, geological and desert is considered the most common sort of natural reserves. There are also 14 suggested natural reserves that have not been declared yet as shown in Fig. (3).
\end{abstract}

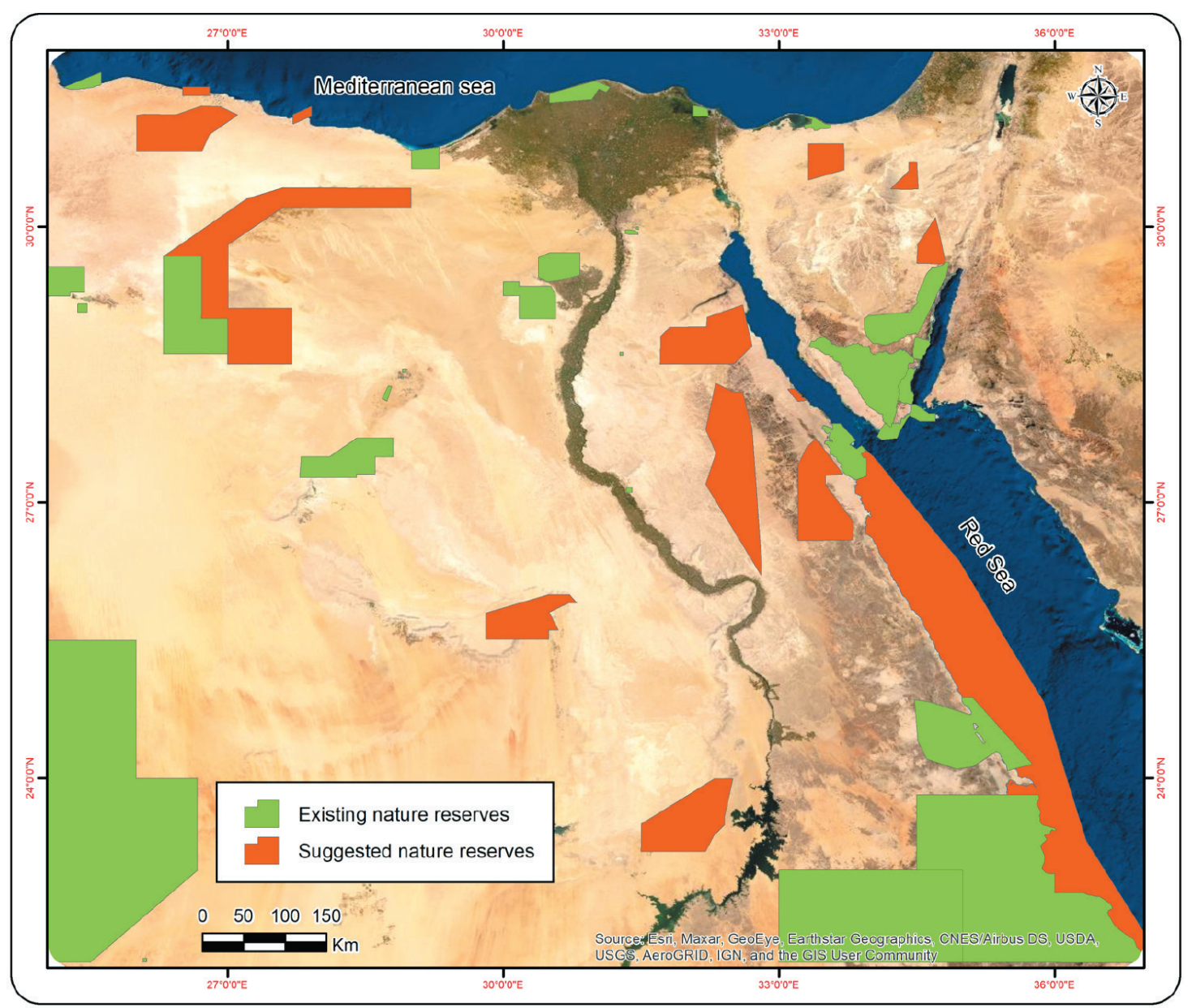

Fig. 3. Study Area Existing and Suggesting Nature Reserves 


\section{Objectives}

There are three objectives for this Study:

- Create an interactive map of natural reserves in Egypt that will be accessible at any time and place.

- Illustrate the stages of producing an interactive map using open-source tools

- Increase awareness about the natural reserves in Egypt.

\section{Methodology \\ 1- Data Collection:}

There are two types of data used: Spatial data and Attribute data. Spatial data is a map (.jpg) for all natural reserves, used to create shapefile by using QGIS (open-source software). Attribute data is divided into two subtypes: qualitative data which includes reserves' names, type, picture name and articles, and quantitative data which includes date of the declaration and area of the natural reserve. All data was collected from the Egyptian environmental affairs agency's official website. Using this information, Spatial and Attribute data were combined. All the previously mentioned data is just for existing natural reserves, and in the case of suggested natural reserves, only names are available.

\section{2- Data Processing:}

While creating a web GIS application, all shape files are uploaded to website using the PostGIS or Geo Server software, but a different approach was taken on this study, which is to convert shape file to GeoJson file (by QGIS), as shown in Fig. 2. Then all the data are added to application using Leaflet Ajax (Metcalf, C, 2016). GeoJSON is a specialization of the JSON data interchange format that can manage georeferenced data using a subset of instructions provided by the JavaScript language (Pasquale, D, et al, 2013), as shown in Fig. (4)

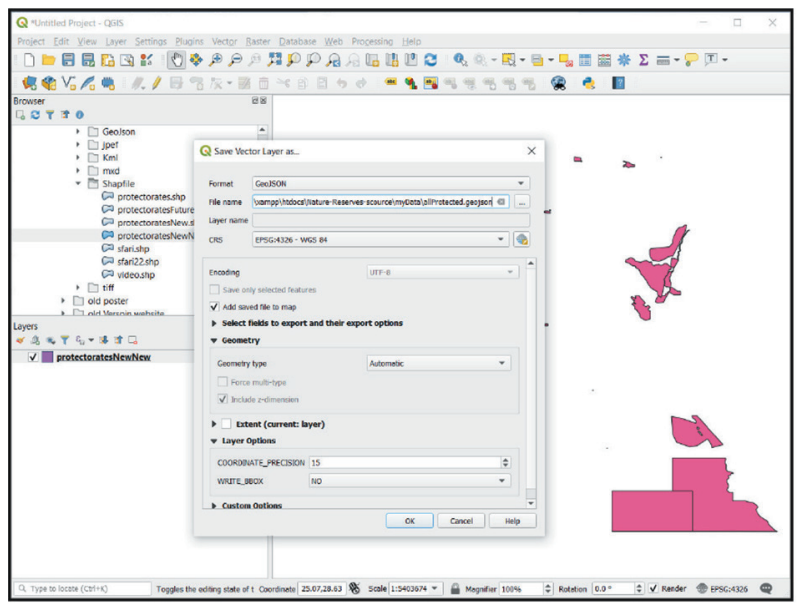

Fig. 4. Converting shape file to Geojson file using QGIS software

\section{3- Web Site Creation:}

When creating the Web site home page in most Web GIS applications, the map covers the entire interface, and a group of buttons are added to the sides or at the top to perform tasks such as showing the map legend or showing tables and other media used. HTML - CSS - JS were used to design home page for interactive map, and several buttons were added on the left or right side (depending on the language) to do many tasks. Leaflet Library files have been downloaded from The official website of the Leaflet library, then added to HTML file, as shown in Fig. (5).

\section{4- Web Map Creation:}

The Leaflet library helps create the framework for adding maps created with name (mymap), after that adding base maps. Three different maps have been added (Open Street Map, Topographic Map, Imagery), and then layers of natural reserves, existing and suggesting, as shown in Fig. (6). 


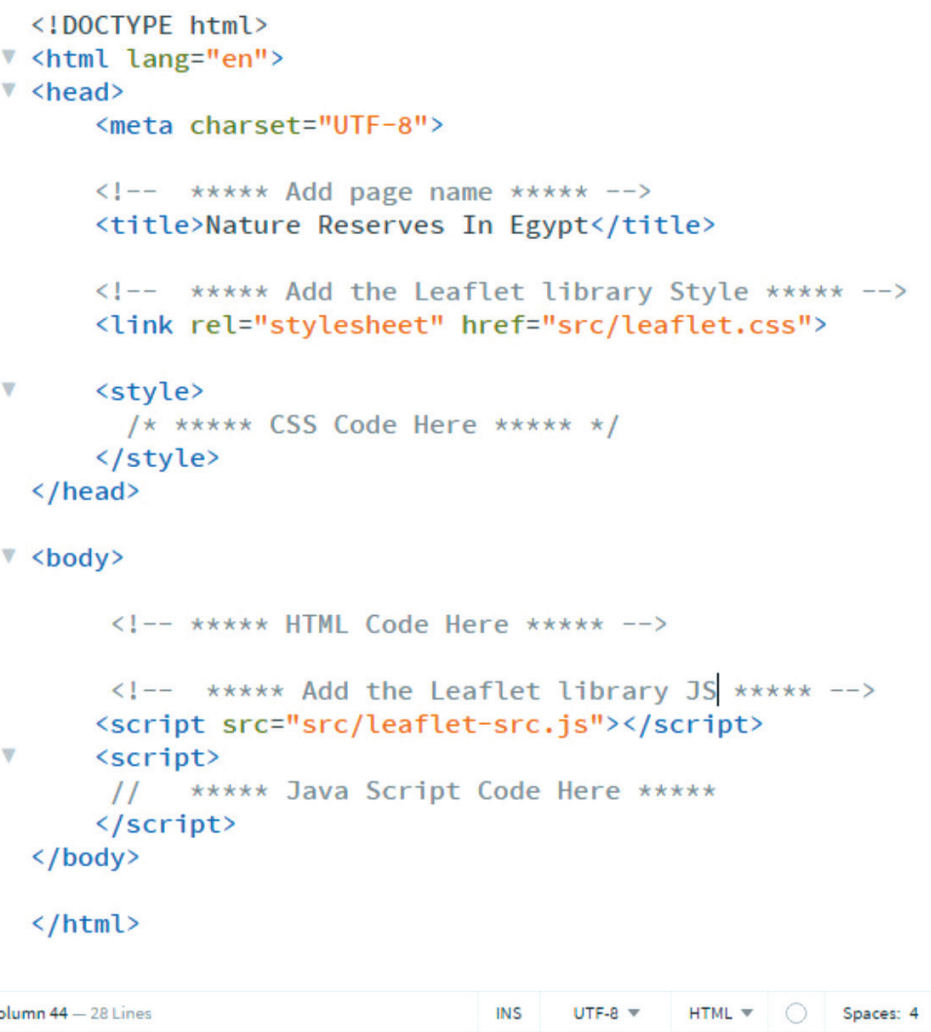

Fig. 5. HTML5 structure index page and links to leaflet.js and leaflet.css files

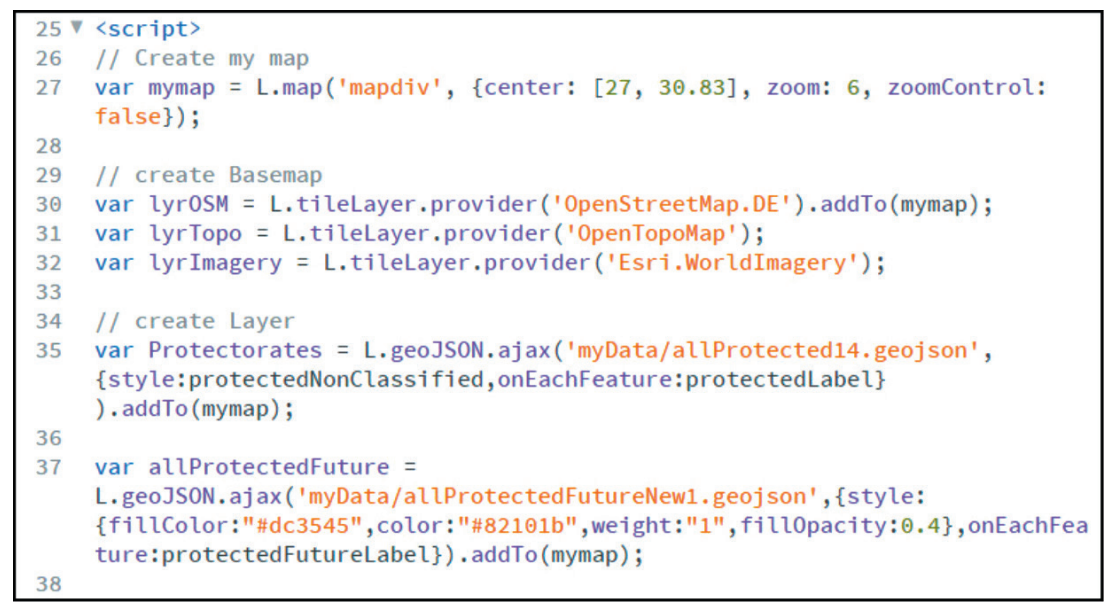

Fig. 6. Create map and add base map and natural reserves layers

\section{5- Control tools Creation:}

The aim of the control tools is interacting with the map. There are tools from the leaflet library itself used. Other tools have been created, and others from plugins have been developed by programmers. All plugins were available for use and development, proving the strength and importance of open-source tools.

\section{Base map \& Layer Control}

Its aim is to enable the user to control base maps and layers, and it one of the tools from the leaflet library. It allows choosing only one of base map from (Radio button) and can choose more than one in layer from (Checkbox).

\section{Side Bar Control}

The sidebar is important in displaying 
information, images, and the map key, in addition to the ability to choose one of the nature reserves to display additional information about it. This tool helps the user to show or hide the sidebar.

The side bar is one of the plugins that have been used (Bieniek T, 2020), and the button used to show or hide side bar is called (easy button). It has been used more than once and it helps the designer add a button Easley. It remains for the designer to create the function for this button (CliffCloud, 2019).

\section{Polyline Measure Control}

It helps the user take measurements on the map, and the unit is shown in meters at the beginning. When it increases more than one $\mathrm{km}$, the unit of measure turns into a kilometre; and it considered one of the plugins that have been used (ppete2, 2019).

\section{Home Location Control}

After touring inside the map, the importance of this tool comes by return to the basic zoom, and map centre.

This tool is created for this map by adding easy button and function for it.

\section{Change Language Control}

Making the map multilingual, this tool was created, to help change the map language to Arabic or English depending on the language used.

\section{6- Nature Reserves Classification Functions:}

When creating distribution maps using GIS software, this is easily done using the tools available, but when creating them programmatically, this is done by writing codes.

There are two types of distribution maps depending on the data type. The first type is Category maps where the "Switch Case function" is used when writing the code because

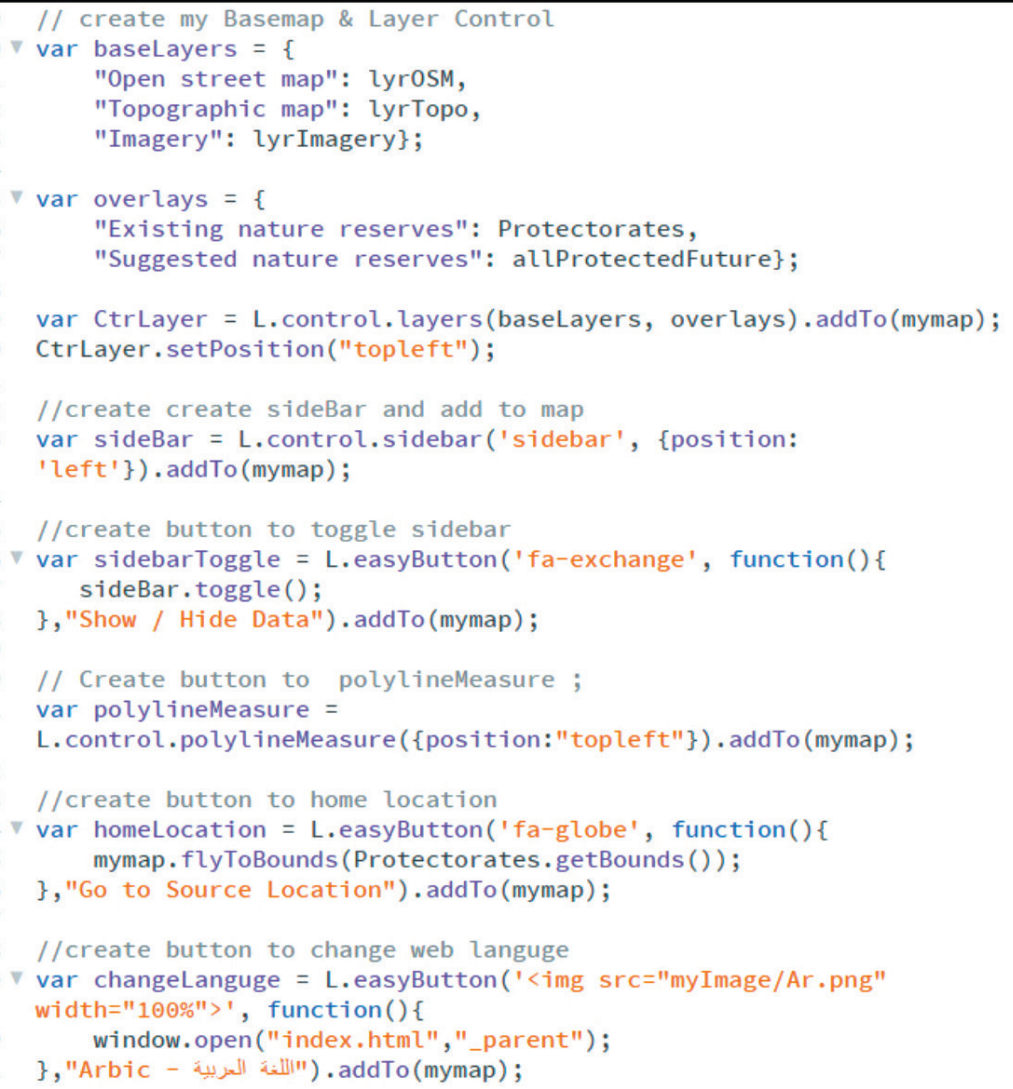

Fig. 7. Create all control tools 
it depends on writing it with unique words that are not repeated. This corresponds to the category maps. The second type is Quantitative maps, where the "If Else function" is used to write the code, as shown in Fig. (8-9).

From the side bar, the user can select the classification for nature reserves (by type, by date of declaration, or without classification).

\section{Online Publishing:}

It is the last stage in which the map designs (all HTML, CSS, JS files) and all data are uploaded to the host website. Netlify is one of the hosts that allow free space for small website, so we used it. The interactive map of natural reserves in Egypt is now available on this link: (https:// nature-reserve.netlify.app/ecopy).

\section{Results:}

- The most important result of the study is the production of an interactive map of natural reserves in Egypt. The map provides the user with data for any natural reserve by selecting its name. The information will be shown on the side area, which includes Name, Type, Date of Declaration, and Area, in addition to an article explaining the importance of the reserve. Its image will also be viewed, as shown in Fig. 7.

- The map is available in both English and Arabic and can be viewed in either language.

- The website is responsive and can be easily accessed via PC, Laptop, Tablet and Mobile.

- When choosing a natural reserve, a "More" button appears. The function of this button is to go to another page with more information, articles, and pictures of the natural reserve. However, this page is available in Arabic only now.

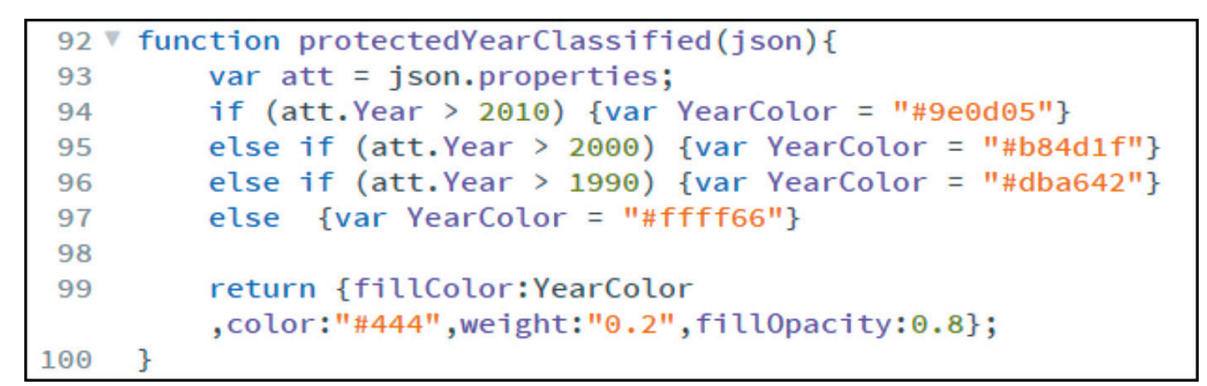

Fig. 8. Using (if else) function for creating Coroblth maps

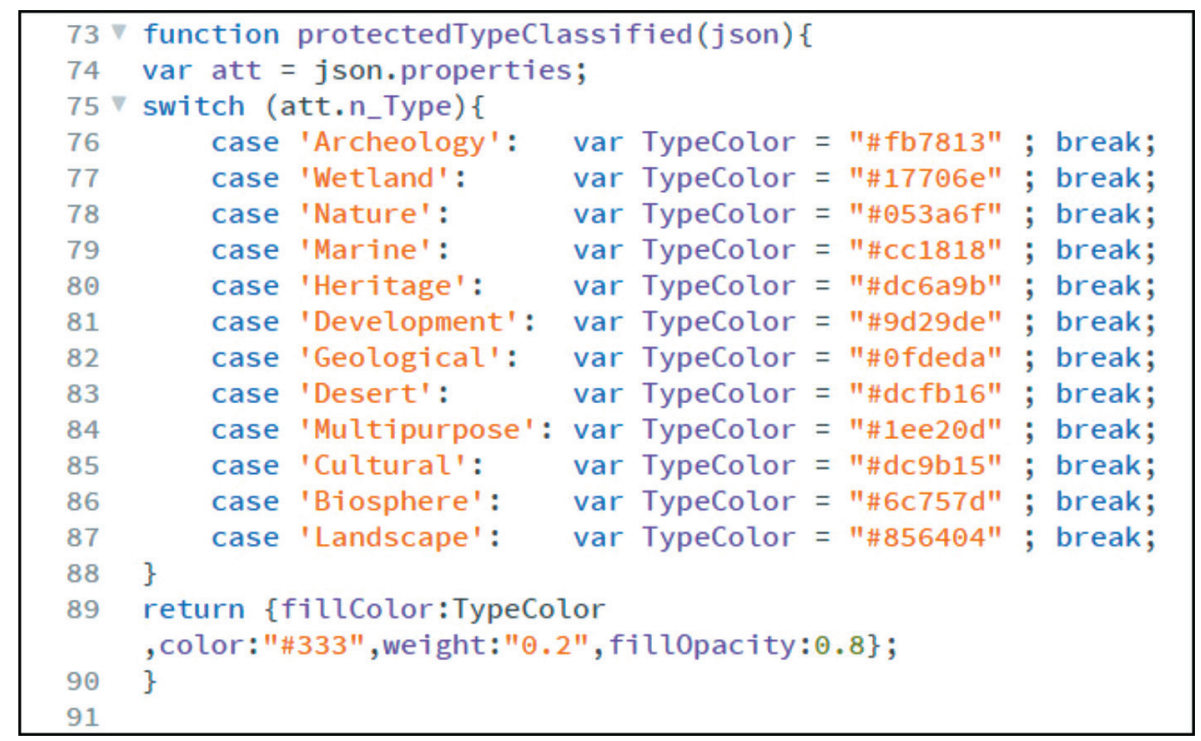

Fig. 9. Using (Switch Case) function for creating category maps 
Prof. Adel Mohamed Shawesh

Dr. Mahmoud Fawzy Farag

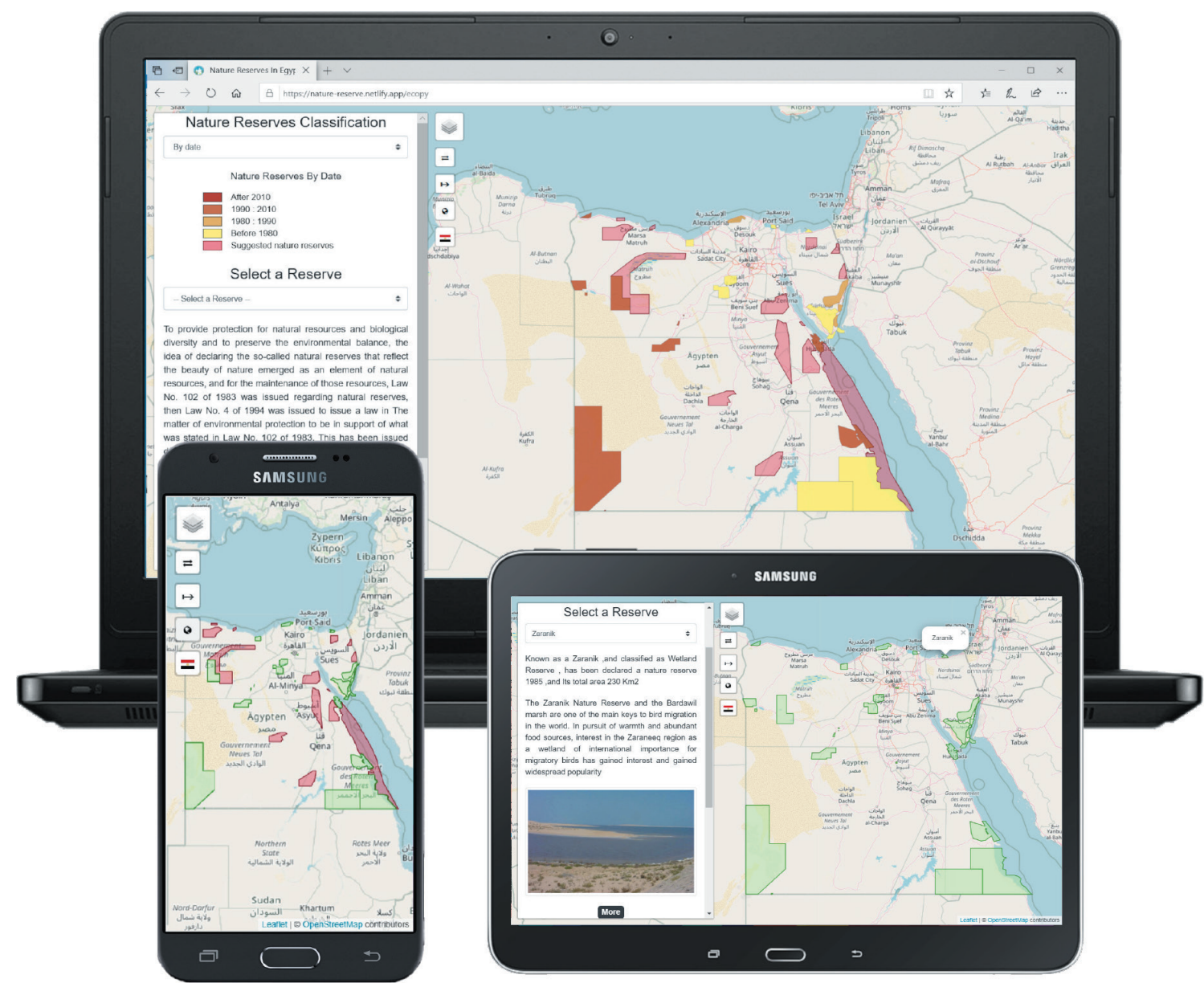

Fig. 10. The interactive map after publishing online displayed on more than one device

\begin{tabular}{|l|l|} 
Open the list of: \\
1-Basemaps (osm, topo map and imagery) \\
(User can choose only one) \\
2- Layers (existing and targeted nature reserves) \\
(User can choose more than one)
\end{tabular}

Fig. 11. Control tools to interact with the map 


\section{Recommendations:}

- Reviewing the Natural Reserves map of the Environmental Affairs Agency, as the study has discovered a difference between it and an open street map.

- Adding interactive maps applications to the geography department's courses in Egyptian universities, in addition to the Geographic Information Systems programming courses.

- Relying on interactive maps and atlases in spreading geographical knowledge in all fields including education, health, tourism, industry, and others.

- Raising geographical research interest in recent topics related to Geographic Information Systems such as (Big Data - Internet of Thing (IOT) - Smart City).

\section{Acknowledgments:}

Special thanks to Mr Osama Mohamed (Elzero Web School) for providing a free explanation of website design on YouTube, thanks for Eng/ Mohamed Abdelwahed, Eng/ Don Jason \& Dr/ Shrouk Khedre for helping in language review.

\section{References}

* Azaz, L, (2019), Qassim Tourist Web GIS, GIS Symposium in Saudi Arabia. 37-47.

* Bieniek, T, (2020), leaflet-sidebar: A responsive sidebar plugin, GitHup.

* Brambilla, G, Amoretti, M, Zanichelli, F, (2017), Adgt.js: a web application framework for peer-to-peer location-based services. In: Desprez, F et al (eds) EUROPAR 2016: parallel processing workshops. Lecture Notes in Computer Science, vol 10104. Springer, Cham.248-259.

* CliffCloud (2019), Leaflet-Easy-Button: way to add buttons with Leaflet, GitHup.

* Donohue, R, Sack C, Roth, R, (2014), Time series proportional symbol maps with Leafet and jQuery. Cartogr Perspect 76:43-66.

* Edler, D, Vetter, M, (2019), The Simplicity of Modern Audiovisual Web Cartography: An Example with the Open-Source JavaScript Library leafet.js, Journal of Cartography and Geographic Information, 69,51-62.

* Farkas, G, (2017a), Practical GIS (Use tools such as QGIS, PostGIS and Geoserver to build powerful Gis Solutions), Packt Publishing, Birmingham.

* Farkas, G, (2017b), Applicability of open-source web mapping libraries for building massive Web GIS clients, Journal of Geographical Systems, 19, 273-295.

* Kawasaki, A, Berman, M, Guan, W, (2012), The growing role of web-based geospatial technology, disaster response and support, $37(2)$.

* Marconcini, S, (2018), ICT as a tool to foster inclusion: Interactive maps to access cultural heritage sites, IOP Conf. Series: Materials Science and Engineering 364,012040 .

* Metcalf, C, (2016), leaflet-ajax: Add GeoJSON data via ajax or jsonp, GitHup.

* Muehlenhaus, I, (2014), Web cartography. Map design for interactive and mobile devices, CRC Press, Boca Raton.

* Nizamuddin, Sofyan, H, Ardiansyah, Pertiwi, D, Handayani, P, (2017), Development of Web GIS for information of renewable energy in Aceh Province after rehabilitation and reconstruction process, IOP Conference Series: Earth and Environmental Science. 56.

* Pasquale, D, Lerario, A, Maiellaro, N, (2013), Open Source Interactive Map of Albania Cultural Heritage, International Conference on Electronic Engineering and Computer Science, IERI Procedia 4, 383-390.

* Peterson, G, (2014), GIS cartography. A guide to effective map design, 2nd edn. CRC Press, Boca Raton. 
* ppete2 (2019), Leaflet-Polyline-Measure: Measure distances of simple and complex polylines, GitHup.

* Quynh, H, Phuong, D, Phuong, N, (2016), webgis technology for management and sharing spatial data of protected area, a case study in xuan lien nature reserve, thanh hoa, Journal of Science and Technology, 54, 460-471.

* Ramsey, P, (2007), The State of Open Source GIS, Technical report, Refractions Research Inc., Suite, 300-1207 Douglas Street Victoria, BC, V8W-2E7.

* Roth, R, (2012), Cartographic Interaction Primitives: Framework and Synthesis, The Cartographic Journal, 49,376-395.

* Romero, O, Ahmed, A, Chassignet, E, Eguiarte, A, (2014), An open-source Java web application to build self-contained web GIS sites, Environmental Modelling \& Software, 62, 210-220.

* Sandinska, Y, (2016), technological principles and mapping applications of web GIS, 6th International Conference on Cartography and GIS, Albena, Bulgaria, 287-296.

* Sarjakoski, L, Sarjakoski T, Koskinen, I, Ylirisku, S, (2009), The Role of Augmented Elements to Support Aesthetic and Entertaining Aspects of Interactive Maps on the Web and Mobile Phones. In: Cartography and Art. Lecture Notes in Geoinformation and Cartography. Springer, Berlin, Heidelberg.

* Singh, H, Bhatia, T, Pateriya, B, (2018), Web GIS Development using Open Source Leaflet and Geoserver Toolkit, International Journal of Computer Science and Technology, Vol. 9, ISSue 3, pages $29-33$.

Singh, H, Gambhir, D, (2014), An Open Source Approach to Build a Web GIS Application, International Journal of Computer Science and Technology, 5,50-52.

* Teslya, N, (2014), Web mapping service for mobile tourist guide, In Open Innovations Association FRUCT, Proceedings of 15th Conference of IEEE, 135-143.

* Wang, K, Mulvenon, S, Stegman, C, Anderson, T, (2008), A Web-Based Interactive Mapping System of State Wide School Performance: Integrating Google Maps API Technology into Educational Achievement Data. Journal of Educational technology systems, 36, 19-28.

* Yu, B, Chao, X, Zhang, Xu, W, Ouyang, $Z$, (2016), Effectiveness of nature reserves for natural forests protection in tropical Hainan: a 20-year analysis. Chinese Geographical Science. 26. 208-215.

* Zerihun, M, (2017), Web Based GIS for Tourism Development Using Effective Free and Open Source Software Case Study: Gondor Town and Its Surrounding Area, Ethiopia, Journal of Geographic Information System, 9, 47-58. 
78 Vol.13 (1) March 2021 